\title{
Change of microstructure of clays due to the presence of heavy metal ions in pore water
}

\author{
X.-F. LIU ${ }^{1}$, N. SAIYOURI ${ }^{1}$, and P.-Y. HICHER ${ }^{1}$ \\ ${ }^{1}$ Institut de Recherche en Génie Civil et Mécanique-GeM, UMR CNRS 6183, Ecole Centrale de \\ Nantes, 1 Rue de la Noë BP 92101, Nantes cedex 3, France
}

The compressibility of engineered barrier clays is, to a large extent, controlled by microstructure change due to the presence of chemical ions in clay-water system. This paper aims to investigate the change of microstructure of clays due to the presence of heavy metal ions in pore water. We use two pure clays (kaolinite and bentonite) in the study. One-dimensional consolidation tests were performed on reconstituted samples, which are prepared with distilled water and three types of heavy metal solutions $\left(\mathrm{Pb}\left(\mathrm{NO}_{3}\right)_{2}, \mathrm{Cu}\left(\mathrm{NO}_{3}\right)_{2}, \mathrm{Zn}\left(\mathrm{NO}_{3}\right)_{2}\right.$,). In order to better understand the impact of chemical pore fluid on microstructure of the two clays, following the consolidation test, scanning electron microscope (SEM) observations and mercury intrusion pore size distribution measurements (MIP) were conducted. Due to the measurement range of MIP, which is only allowed to measure the minimal pore size $20 \AA$, BET method by gas sorption, whose measurement pore size range is from $3.5 \AA$ to $500 \AA$, is used to measure the micropore size distribution. By this method, specific surface area of the soils can be also determined. It can be employed to demonstrate the difference of creep performance between the soils. Furthermore, a series of batch equilibrium tests were conducted to better understand the physical-chemical interactions between the particles of soils and the heavy metal ions. With the further consideration of the interparticle electrical attractive and repulsive force, an attempt has been made to predict the creep behaviour by using the modified Gouy-Chapman double layer theory. The results of calculation were compared with that of tests. The comparison shows that the prediction of compressibility of the clays according to the modified double diffuse layer theory can be reasonably agreement with the experimental data.

Key words: microstructure, BET method, clay, heavy metal contaminant, consolidation

\section{Batch test procedures}

According to the ASTM-D4319 norm, the batch tests were conducted respectively with two clays (kaolinite and bentonite) and copper nitrate, lead nitrate and Zinc nitrate solutions. Six solutions for each heavy metal with concentrations varying from 0.1 to $10 \mathrm{mM}$ were prepared. Their $\mathrm{pH}$ was adjusted to 5 by adding $\mathrm{HCl}$ and/or $\mathrm{NaOH}$. Samples were prepared by mixing $2 \mathrm{~g}$ of air-dried kaolinite and bentonite powders with $20 \mathrm{ml}$ of every single prepared solution. The equilibration time was tested in preliminary experiments and was found close to 48 hours while the samples were gently agitated. Once equilibrated, samples were centrifuged for $20 \mathrm{~min}$ at $2000 \mathrm{~g}$ to separate the solid from the dissolved phases. heavy metals concentrations in the dissolved phase were finally analyzed using an atomic adsorption spectrophotometer (Shimadzu AA-6300). 


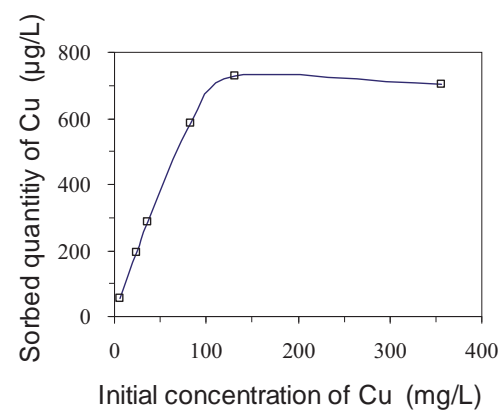

FIG. 1. Sorption of $\mathrm{Cu}$ in different initial concentrations of copper nitrate

\section{Consolidation test procedures}

Consolidation test were conducted according to the ASTM-D2435 norm. Four suspensions for each clay were prepared by mixing air-dried tested clay powders with (i) distilled water, (ii) $10 \mathrm{mM}$ of $\mathrm{Cu}\left(\mathrm{NO}_{3}\right)_{2}$ solutions, (iii) $10 \mathrm{mM}$ of $\mathrm{Pb}\left(\mathrm{NO}_{3}\right)_{2}$ and (iv) $10 \mathrm{mM}$ of $\mathrm{Zn}\left(\mathrm{NO}_{3}\right)_{2}$ solutions. The suspensions were slowly poured into a consolidameter $(30 \mathrm{~cm}$ height $\mathrm{x} 10 \mathrm{~cm}$ diameter). The preconsolidation lasted about five days under a vertical pressure of $20 \mathrm{kPa}$ and double drainage condition until the steady vertical settlement was achieved. Following the completion of preconsolidation, samples were carefully trimmed into a suitable size for conventional oedometer tests $(19 \mathrm{~mm}$ height $\mathrm{x} 70 \mathrm{~mm}$ diameter). The tests were performed by applying incremental loading from $5 \mathrm{kPa}$ to $800 \mathrm{kPa}$. The successive loading was twice of previous one and each loading and unloading lasted for $24 \mathrm{~h}$.

\section{MIP test and BET}

Samples for MIP and BET were carefully trimmed into small cubes $(10 \times 10 \times 10 \mathrm{~mm})$ after preconsolidation and 1D oedometer tests. In order to prevent the capillary shrinkage, the samples were freeze-dried. The MIP device is a Micromeritics AutoPore 9500 with a maximum intrusion pressure of $210 \mathrm{MPa}$ and permit to determine the distribution of radii from $3 \mathrm{~nm}$ to $360 \mu \mathrm{m}$. The pore distribution of clays using BET method is determined by the Gemini V Analyzer of micromeritics.

\section{SEM observation}

Fresh fragments produced by breaking carefully the (pre)consolidated samples were directly analyzed for their microstructure by using an environmental SEM.

\section{References}

1. Mesri, G., and Olson, R. E. (1971). Clays, Clay Miner., 19, 151-158.

2. Olson, R. E. and Mesri, G., (1970). ASCE J Soil Mech. Found Div. 96(6): 1863-1878.

3. Petrov, R.J., Rowe, R.W., 1997. Canadian Geotechnical Journal 34, 863-885.

4. Sridharan A, Jayadeva MS (1982), Géotechnique 32(2):133-144.

5. Pierre Delage, Experimental Unsaturated Soil Mechanics, 2007, 11-32. 